\title{
A role for islet neogenesis in curing diabetes
}

\author{
G. L. Pittenger • D. Taylor-Fishwick • A. I. Vinik
}

Received: 22 January 2009 / Accepted: 10 February 2009/Published online: 7 March 2009

(C) Springer-Verlag 2009

Keywords EGF-Gastrin · GLP-1 · INGAP - Islet regeneration · Islet transplant · Type 1 diabetes · Type 2 diabetes

$\begin{array}{ll}\text { Abbreviations } \\ \text { EGF } & \text { Epidermal growth factor } \\ \text { ESC } & \text { Embryonic stem cell } \\ \text { GLP-1 } & \text { Glucagon-like peptide } 1 \\ \text { INGAP } & \text { Islet neogenesis-associated protein }\end{array}$

Endogenous insulin deficiency is the tie that binds all forms of diabetes. Definitive treatment or cure of type 1 and type 2 diabetes cannot occur without a durable reversal of relative or absolute endogenous insulin deficiency. Current efforts to restore physiological insulin secretion include (1)

\footnotetext{
G. L. Pittenger $\cdot$ D. Taylor-Fishwick $\cdot$ A. I. Vinik

Department of Internal Medicine, Eastern Virginia Medical School,

Norfolk, VA, USA

G. L. Pittenger · A. I. Vinik

Department of Pathology and Anatomy,

Eastern Virginia Medical School,

Norfolk, VA, USA

G. L. Pittenger $(\varangle) \cdot$ D. Taylor-Fishwick $\cdot$ A. I. Vinik

The EVMS Strelitz Diabetes Center,

855 West Brambleton Avenue,

Norfolk, VA 23510, USA

e-mail: PittenGL@evms.edu

D. Taylor-Fishwick

Department of Immunology and Microbiology,

Eastern Virginia Medical School,

Norfolk, VA, USA
}

islet or pancreas transplant; (2) exogenous cell therapies, including differentiation of bone marrow cells and embryonic stem cells (ESCs); and (3) islet regeneration from endogenous pancreatic cells. Although they would represent advances, islet or beta cell transplant $[1,2]$, the artificial pancreas [3, 4], gene therapy [5], and even stem cell therapy $[6,7]$ cannot be considered restorative approaches unless the results are durable and have an acceptable safety profile.

Islet transplantation, both allo- and xeno-, as a means of reversing diabetes has been limited by graft durability and/ or donor supply, as well as the complications of surgery and immunosuppression. However, progress is being made to resolve these issues [1,8]. Minimally invasive techniques for the transplant of donor islets into the liver have been developed, and extensive studies have refined the immunosuppression required for transplant survival. At present, the limiting problem for islet transplantation is obtaining sufficient islets for the broad application of the technique. It is hoped that work with stem cells will resolve this issue.

Early studies showed that ESCs did not achieve terminal differentiation and had a low insulin content and a poor response to glucose. Growth of the islet-like clusters from ESCs was unbridled and, despite production of insulin, they failed to cure diabetic mice [9]. Israeli scientists found insulin-producing cells in embryoid bodies formed spontaneously from ESCs when they stop growing, but these did not make sufficient insulin to reverse diabetes [10]. Soria and colleagues used gene-trapping techniques to isolate insulin-producing cells and transfected an antibiotic resistance gene adjoined to the insulin promoter. When these cells formed three-dimensional structures, the cells increased insulin production to therapeutic levels but insulin secretion remained insensitive to glucose [11]. More recent 
work has significantly improved the prospects for ESCs as a source of cells for transplant. For example, in a series of studies from a group at Novocell (San Diego, CA, USA), ESCs were first differentiated into pancreatic endoderm, which could subsequently be induced to differentiate into glucose-sensitive insulin-secreting cells capable of protecting mice from streptozotocin-induced diabetes $[12,13]$. The cells exhibited characteristics of beta cells and produced circulating human insulin and C-peptide in transplanted mice. However, ethical considerations constitute barriers to the widespread availability of ESCs, which could potentially provide a viable alternative source of beta cells.

Another approach is the development of new islets from progenitor cells residing in the pancreas, termed islet neogenesis. Advances in our understanding of pancreatic embryogenesis and the maintenance of pancreatic endocrine tissue in adults have led to an appreciation of islet neogenesis as a promising, and perhaps more immediate, technology for restoring normal insulin secretion. In the 1980s, a model for islet neogenesis in adult mammalian pancreas, developed by Rosenberg et al., showed that pancreatic ductal cells can be induced to differentiate into normal functioning adult endocrine cells [14]. More recent studies have confirmed this concept, demonstrating that progenitor cells located in the ductal epithelium of the pancreas can be stimulated to develop into newly formed beta cells and that these cells can be isolated for further study [5]. When the tail of the pancreas in Balb/c mice was ligated, there was an increase in the expression of Neurog3, one of the earliest markers of islet differentiation. This was accompanied by a doubling in beta cell mass, reflecting induction of neogenesis, which led to isolation of endocrine progenitor cells from the pancreatic duct epithelium. Lineage tracing has recently confirmed the development of endocrine tissue from duct cells in a duct ligation model [15]. A great deal of interest is now being focused on the factors responsible for the initiation of growth, growth proliferation, differentiation into adult endocrine cells, growth cessation and cell maintenance.

Studies of models of islet neogenesis have shown that the acinar cell product known as islet neogenesis-associated protein (INGAP) is found in pancreatic exocrine secretions and appears to stimulate the growth and proliferation of duct cells and their differentiation into endocrine cells [16, 17]. INGAP and a bioactive 15 amino acid synthetic peptide (INGAP peptide) have been shown to be inducers of islet neogenesis in a human islet system [18]. INGAP peptide has shown evidence of islet neogenesis activity across multiple species, including monkeys [19]. Rosenberg et al. showed that INGAP peptide can reverse a mouse model of diabetes induced by streptozotocin [20]. Recent reports of human studies with INGAP peptide exemplify one of the few efforts to develop not just a palliative approach to diabetes, but a restorative one. These trials showed a reduction in $\mathrm{HbA}_{1 \mathrm{c}}$ level of approximately $1 \%$ in type 2 diabetic patients and a statistically significant improvement in endogenous insulin secretion in type 1 diabetic patients after 3 months of treatment (J. B. Buse, K. Dungan, R. Ratner, unpublished data). Because these trials did not reverse insulin dependence, they suggest a potential need to address ongoing islet pathologies alongside induction of islet neogenesis. Information on this therapeutic approach has recently been extended by the demonstration that a combination of INGAP and lisofylline, an immunomodulator, can reverse established type 1 diabetes in NOD mice used as a model of the condition [21]. The reversal is accompanied by histological evidence of new islet formation. Furthermore, reports from several groups provide supporting evidence for the development of INGAP peptide as a therapy for type 2 diabetes [16, 22, 23]. INGAP peptide, alone or in combination with an immunomodulatory agent, may be a bona fide candidate for treating both type 1 and type 2 diabetes, removing the need for insulin treatment.

Other stimuli have been demonstrated to exert neogenic effects on the endocrine pancreas. The combination of epidermal growth factor (EGF) and gastrin has been shown to stimulate islet neogenesis in both animal and human studies [24]. EGF, however, is a powerful non-specific growth factor that is implicated in carcinogenesis and may not be a good candidate for a drug. Exenatide, a long-acting analogue of glucagon-like peptide 1 (GLP-1), has shown evidence of induction of islet neogenesis in rodents [25], although exenatide did not show evidence of islet neogenesis in a chronic non-human primate toxicology study, and no such activity has been reported during the marketed use of exenatide. Islet neogenesis has been reported in human pancreatic tissue transplanted into NOD/severe combined immunodeficient mice in response to GLP-1 and gastrin [26]. Of interest, neither agent alone reduced hyperglycaemia in the mice. In the report from $\mathrm{Xu}$ et al., transfection of Neurog3 into pancreatic duct cells also stimulated islet neogenesis [5]. Thus, there are a number of agents that may enhance islet neogenesis from pancreatic duct progenitor cells in the mature pancreas. Finding the best combination for normalisation of blood glucose is the next step towards ameliorating diabetes.

It has been questioned whether or not islet neogenesis from progenitor cells occurs in the adult pancreas [27], but this debate is coming to a close. Human islet tissue has been shown to be able to revert to duct-like structures, which can be induced back to 'neoislets' [28]. This system has been adapted to measure islet neogenesis as a pharmacological activity as well as to elucidate the provenance of islet tissue $[18,28]$. Application of growthpromoting substances to ductal cells in culture have 
stimulated these to grow and express $P D X 1$, which encodes the transcription factor necessary for endocrine cell development $[29,30]$. At this stage, adding matrigel with a switch to a medium containing keratinocyte growth factor and nicotinamide induces the cells to form cultivated human islet buds that produce a small amount of insulin in response to glucose. The biggest limitation was the inability to form the number of cells required to reverse diabetes.

In a recent paradigm shift, differentiated adult pancreatic exocrine cells were induced to de-differentiate and subsequently re-differentiate to become beta cell-like [31]. Intriguingly, in a manner analogous to the conversion of adult cells into induced pluripotent stem cells, this conversion was achieved by the introduction of a small number of transcription factors. Key signalling pathways associated with de-/re-differentiation from mouse exocrine cells have been identified [31] and have been implicated in the process of islet neogenesis $[14,32]$. Clearly, results in this area, while important, are at an early stage. The drawbacks to therapies based on this paradigm include their reliance on virus vectors to efficiently deliver transcription factors to target cells. Moreover, treatment must be continued for maintenance of an adequate pool of insulinsecreting cells. Furthermore, the immunological characteristics of the re-differentiated cells need to be studied to determine whether acinar cell conversion offers an acceptable alternative to islet transplant, which is clinically tested and does not involve gene therapy. While in situ conversion of exocrine pancreatic cells has the advantage of achieving beta cell function in the pancreas, not in the liver, as is the case for islet transplantation, the process has so far only resulted in the generation of isolated beta cells, not islets. These beta cells do not organise into islet-like structures and are devoid of other islet cells that secrete other hormones important for metabolic control. Nevertheless, this technology could offer a solution to the current problem of the limited availability of functional beta cells. While clinical trials of this approach are years away, investigations to date have demonstrated that the simple introduction of a small number of transcription factors can alter cell type. Decades may be required to fully understand the benefits and risks of this technology, but it does offer the exciting possibility of achieving patient-specific cell therapies.

Rather than struggle with the propensity of nonpancreatic stem cells to revert to their former state and the difficulties of identifying the necessary control mechanisms for transitioning ESCs into pancreatic stem cells, it appears that we need look no further than the pancreas itself as a source of more advanced stem or progenitor cells. There is now abundant evidence that cells in the pancreas can be coaxed to develop by pharmacological means not just into beta cells, but also into normal islets. The questions are: With what cells do you start, how do you treat them, and what do you get? Why, then, not harness nature's cascade of events that underlie the normal development and maintenance of pancreatic endocrine tissue? It is an investigational road that has been less travelled, but may more quickly lead to reversing a root cause of all forms of diabetes.

Duality of interest The authors are co-inventors of INGAP and INGAP-related technologies.

\section{References}

1. Hogan A, Pileggi A, Ricordi C (2008) Transplantation: current developments and future directions; the future of clinical islet transplantation as a cure for diabetes. Front Biosci 13:1192-1205

2. Ricordi C, Edlund H (2008) Toward a renewable source of pancreatic beta-cells. Nat Biotechnol 26:397-398

3. Weinzimer SA, Steil GM, Swan KL, Dziura J, Kurtz N, Tamborlane WV (2008) Fully automated closed-loop insulin delivery versus semiautomated hybrid control in pediatric patients with type 1 diabetes using an artificial pancreas. Diabetes Care 31:934-939

4. Weinzimer SA, Tamborlane WV (2008) Sensor-augmented pump therapy in type 1 diabetes. Curr Opin Endocrinol Diabetes Obes $15: 118-122$

5. Xu X, D'Hoker J, Stange G et al (2008) Beta cells can be generated from endogenous progenitors in injured adult mouse pancreas. Cell 132:197-207

6. Chen C, Zhang Y, Sheng X, Huang C, Zang YQ (2008) Differentiation of embryonic stem cells towards pancreatic progenitor cells and their transplantation into streptozotocininduced diabetic mice. Cell Biol Int 32:456-461

7. Liu M, Han ZC (2008) Mesenchymal stem cells: biology and clinical potential in type 1 diabetes therapy. J Cell Mol Med 12:1155-1168

8. Fiorina P, Shapiro AM, Ricordi C, Secchi A (2008) The clinical impact of islet transplantation. Am J Transplant 8:1990-1997

9. Lumelsky N, Blondel O, Laeng P, Velasco I, Ravin R, McKay R (2001) Differentiation of embryonic stem cells to insulin-secreting structures similar to pancreatic islets. Science 292:1389-1394

10. Assady S, Maor G, Amit M, Itskovitz-Eldor J, Skorecki KL, Tzukerman M (2001) Insulin production by human embryonic stem cells. Diabetes 50:1691-1697

11. Soria B, Roche E, Berna G, Leon-Quinto T, Reig JA, Martin F (2000) Insulin-secreting cells derived from embryonic stem cells normalize glycemia in streptozotocin-induced diabetic mice. Diabetes 49:157-162

12. D'Amour KA, Bang AG, Eliazer S et al (2006) Production of pancreatic hormone-expressing endocrine cells from human embryonic stem cells. Nat Biotechnol 24:1392-1401

13. Kroon E, Martinson LA, Kadoya K et al (2008) Pancreatic endoderm derived from human embryonic stem cells generates glucose-responsive insulin-secreting cells in vivo. Nat Biotechnol 26:443-452

14. Rosenberg L, Duguid WP, Brown RA, Vinik AI (1988) Induction of islet cell proliferation will reverse diabetes in the Syrian golden hamster. Diabetes 37:334-341 
15. Inada A, Nienaber $C$, Katsuta $H$ et al (2008) Carbonic anhydrase II-positive pancreatic cells are progenitors for both endocrine and exocrine pancreas after birth. Proc Natl Acad Sci USA 105:19915-19919

16. Pittenger GL, Taylor-Fishwick DA, Johns RH, Burcus N, Kosuri S, Vinik AI (2007) Intramuscular injection of islet neogenesisassociated protein peptide stimulates pancreatic islet neogenesis in healthy dogs. Pancreas 34:103-111

17. Rafaeloff R, Pittenger GL, Barlow SW et al (1997) Cloning and sequencing of the pancreatic islet neogenesis associated protein (INGAP) gene and its expression in islet neogenesis in hamsters. J Clin Invest 99:2100-2109

18. Hanley SC, Pilotte A, Massie B, Rosenberg L (2008) Cellular origins of adult human islet in vitro dedifferentiation. Lab Invest 88:761-772

19. Fleming A, Rosenberg L (2007) Prospects and challenges for islet regeneration as a treatment for diabetes: a review of islet neogenesis associated protein. J Diabetes Sci Tech 1:231-244

20. Rosenberg L, Lipsett M, Yoon JW et al (2004) A pentadecapeptide fragment of islet neogenesis-associated protein increases betacell mass and reverses diabetes in C57BL/6J mice. Ann Surg 240:875-884

21. Fleming A (2008) What will it take to get therapies approved for type 1 diabetes? Ann N Y Acad Sci 1150:25-31

22. Borelli MI, Stoppiglia LF, Rezende LF et al (2005) INGAPrelated pentadecapeptide: its modulatory effect upon insulin secretion. Regul Pept 131:97-102

23. Taylor-Fishwick DA, Bowman A, Hamblet N, Bernard P, Harlan DM, Vinik AI (2006) Islet neogenesis associated protein transgenic mice are resistant to hyperglycemia induced by streptozotocin. J Endocrinol 190:729-737
24. Suarez-Pinzon WL, Lakey JR, Brand SJ, Rabinovitch A (2005) Combination therapy with epidermal growth factor and gastrin induces neogenesis of human islet $\beta$-cells from pancreatic duct cells and an increase in functional $\beta$-cell mass. J Clin Endocrinol Metab 90:3401-3409

25. Tourrel C, Bailbe D, Meile MJ, Kergoat M, Portha B (2001) Glucagon-like peptide-1 and exendin-4 stimulate beta-cell neogenesis in streptozotocin-treated newborn rats resulting in persistently improved glucose homeostasis at adult age. Diabetes 50:1562-1570

26. Suarez-Pinzon WL, Lakey JR, Rabinovitch A (2008) Combination therapy with glucagon-like peptide-1 and gastrin induces beta-cell neogenesis from pancreatic duct cells in human islets transplanted in immunodeficient diabetic mice. Cell Transplant 17:631-640

27. Dor Y, Brown J, Martinez OI, Melton DA (2004) Adult pancreatic beta-cells are formed by self-duplication rather than stem-cell differentiation. Nature 429:41-46

28. Jamal AM, Lipsett M, Sladek R, Laganiere S, Hanley S, Rosenberg L (2005) Morphogenetic plasticity of adult human pancreatic islets of Langerhans. Cell Death Differ 12:702-712

29. Bonner-Weir S, Taneja M, Weir GC et al (2000) In vitro cultivation of human islets from expanded ductal tissue. Proc Natl Acad Sci USA 97:7999-8004

30. Yatoh S, Dodge R, Akashi T et al (2007) Differentiation of affinity-purified human pancreatic duct cells to beta-cells. Diabetes 56:1802-1809

31. Zhou Q, Brown J, Kanarek A, Rajagopal J, Melton DA (2008) In vivo reprogramming of adult pancreatic exocrine cells to betacells. Nature 455:627-632

32. Rosenberg L, Vinik AI (1989) Induction of endocrine cell differentiation: a new approach to management of diabetes. J Lab Clin Med 114:75-83 